\title{
Effect of forming methods on porosity and compressive strength of polysiloxane-derived porous silicon carbide ceramics
}

\author{
Jung-Hye EOM, Young-Wook KIM, ${ }^{\dagger}$ Chul B. PARK* and Chunmin WANG** \\ Functional Ceramics Laboratory, Department of Materials Science and Engineering, The University of Seoul, Seoul 130-743, Korea \\ *Microcellular Plastics Manufacturing Laboratory, Department of Mechanical and Industrial Engineering, \\ University of Toronto, Toronto, Ontario, M5S 3G8, Canada \\ ** SABIC-Innovative Plasties, SFS, Shanghai 200040, China
}

\begin{abstract}
Open-cell silicon carbide foams were fabricated from a blend of carbon-filled polysiloxane using three different plastic forming methods: compression molding, injection molding, and extrusion. Compression molding process led to more homogeneous microstructure than the other forming methods, resulting in superior compressive strength (20.6 MPa at $72.4 \%$ porosity). In contrast, extrusion molding led to higher porosity $(\sim 84 \%)$ than the other forming methods $(72-74 \%)$ as a result of a higher level of expansion of expandable microspheres. Injection molding process led to a partial segregation of expanded microspheres and resulted in moderate compressive strength $(9.1 \mathrm{MPa}$ at $74.1 \%$ porosity).
\end{abstract}

(๑2012 The Ceramic Society of Japan. All rights reserved.

Key-words : SiC, Porous ceramics, Forming, Polysiloxane

[Received December 21, 2011; Accepted February 28, 2012]

Porous silicon carbide $(\mathrm{SiC})$ ceramics have a unique set of characteristics, such as high thermal shock resistance, chemical stability, high specific strength, and controlled permeability. Thus, these materials have attracted considerable interest for use in the field of filters for diesel particulates, molten metals and hot gases, gas burner media, vacuum chucks, preforms for metalmatrix composites, membrane supports for hydrogen separation, and lightweight structural materials. ${ }^{1)-14)}$ Recently, various processing methods for producing porous $\mathrm{SiC}$ ceramics using preceramic polymers have been developed because of the advantages of polymer processing routes compared to ceramic powder processes. The advantages include (i) low processing temperatures compared to high temperatures required for the sintering of ceramic powders, ${ }^{14)-16)}$ (ii) use of low cost plastic forming techniques such as compression molding, injection molding, and extrusion; ${ }^{17), 18)}$ (iii) easy handling before heat treatment since preceramic polymers can effectively bind the parts at low temperatures; ${ }^{15), 19)}$ (iv) utilization of unique polymeric properties that cannot be found in ceramic powders such as appreciable plasticity, in situ gas evolution ability, appreciable $\mathrm{CO}_{2}$ solubility, and appreciable solubility of preceramic polymers in organic solvents; ${ }^{20)-23)}$ and (v) ceramic products containing a unique combination of polymer-like nano structures with ceramic-like properties, such as good hardness, creep resistance and oxidation resistance. ${ }^{11), 15)}$

Typical examples of processing strategies for porous $\mathrm{SiC}$ ceramics utilizing the above properties are the direct foaming of polysiloxane/polyurethane solutions, ${ }^{22)}$ self-blowing of a poly(silsesquioxane) melt, ${ }^{20}$ ) and direct foaming of polysiloxane polymers using $\mathrm{CO}_{2} \cdot{ }^{21), 24)}$ Various plastic forming technologies can also be applied to the polysiloxane with or without ceramic fillers to produce $\mathrm{SiC}$ foams; for example compression molding, ${ }^{17}$ ) injection molding, ${ }^{25), 26)}$ extrusion, ${ }^{18)}$ and steam chest molding. ${ }^{27)}$

This paper firstly reports the effect of plastic forming methods on porosity and compressive strength of the porous $\mathrm{SiC}$ ceramics

Corresponding author: Y.-W. Kim; E-mail: ywkim@uos.ac.kr fabricated from carbon-filled polysiloxane. Open-cell silicon carbide foams were fabricated from a blend of carbon-filled polysiloxane using three different plastic forming methods: compression molding, injection molding, and extrusion. The fabrication process involved the following steps: (1) forming of a mixture of polysiloxane, carbon black (carbon source), $\mathrm{Al}_{2} \mathrm{O}_{3}-$ $\mathrm{Y}_{2} \mathrm{O}_{3}$ (sintering additives), and expandable microspheres (sacrificial templates) by compression molding, injection molding, or extrusion; (2) transforming the polysiloxane by pyrolysis into silicon oxycarbide; and (3) fabricating $\mathrm{SiC}$ foams by carbothermal reduction and subsequent sintering.

The raw materials used in this experiment were commercially available polysiloxane (YR3370, GE Toshiba Silicones Co., Ltd., Tokyo, Japan), carbon black (Corax MAF, Korea Carbon Black Co., Ltd., Inchon, Korea), expandable microspheres (091DU40, Expancel, Sundsvall, Sweden), $\mathrm{Al}_{2} \mathrm{O}_{3}$ (AKP30, Sumitomo Chemical Co., Tokyo, Japan), and $\mathrm{Y}_{2} \mathrm{O}_{3}$ (Shin-Etsu Chemical Co., Tokyo, Japan). The expandable microspheres consisted of a thermoplastic shell encapsulating a hydrocarbon droplet. A batch was prepared by ball-milling a mixture of 74.8 mass $\%$ polysiloxane, 10.5 mass $\%$ carbon black, 10.0 mass $\%$ expandable microspheres, 1.9 mass $\% \mathrm{Al}_{2} \mathrm{O}_{3}$, and 2.8 mass $\% \mathrm{Y}_{2} \mathrm{O}_{3}$.

For compression-molded samples, the above batch was molded under a compressive pressure of $28 \mathrm{MPa}$ and the molded compacts were expanded by heating the compacts to $150^{\circ} \mathrm{C}$ in air. When heated, the microspheres in the compacts expanded and the polysiloxane softened, resulting in a dramatic volume increase of the compacts.

For injection-molded samples, an injection molding machine was directly connected with a twin-screw extruder. The starting materials were supplied to the twin-screw extruder and the mixture was then forwarded to the injection molding subsystem which was heated to $150^{\circ} \mathrm{C}$. Utilizing a shut-off nozzle, the mixture is accumulated inside the accumulator and then the metered mixture is injected to the shaping mold through a specific nozzle. The inside diameter and height of the shaping mold were $12.6 \mathrm{~mm}$ and $25.2 \mathrm{~mm}$, respectively. 

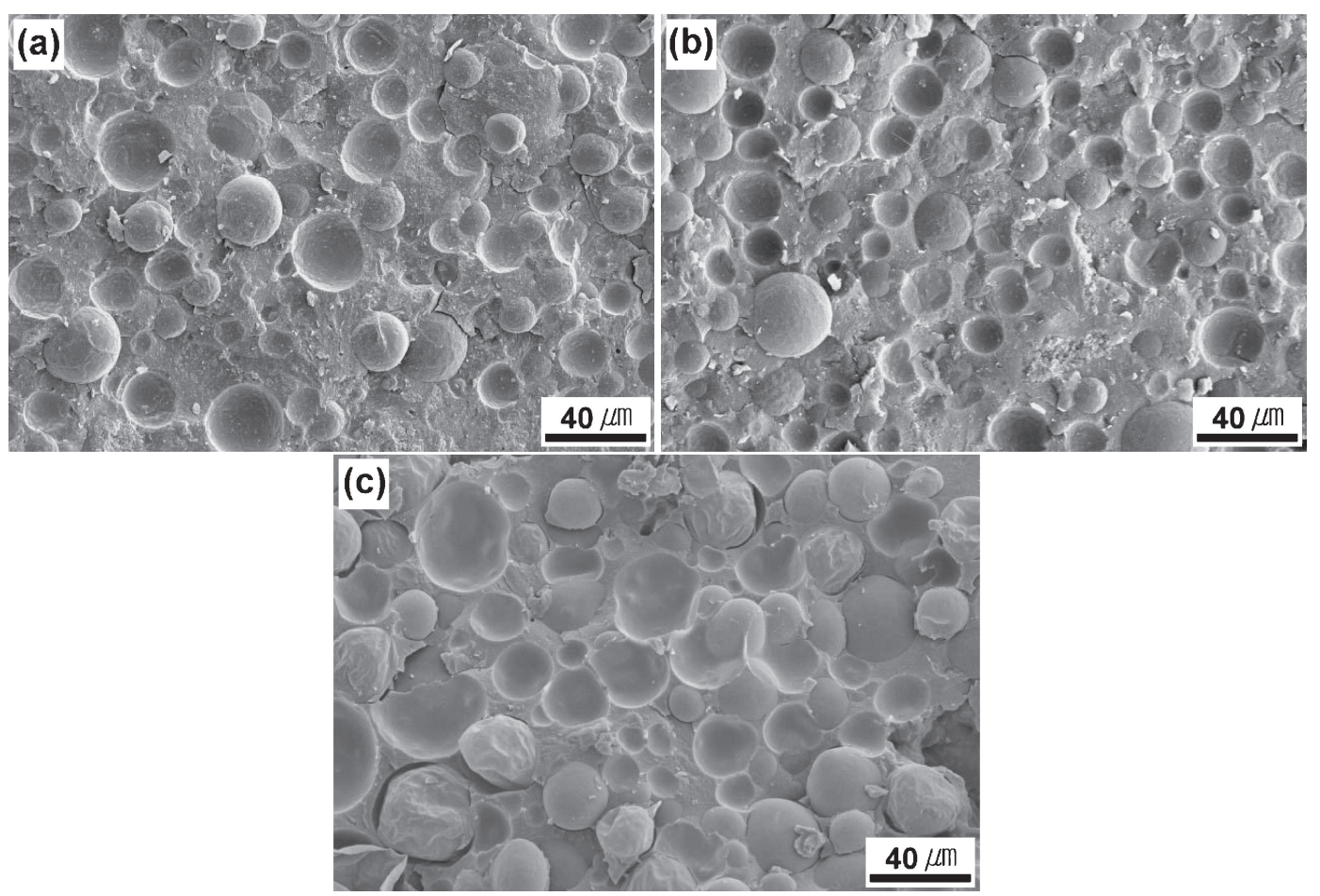

Fig. 1. Typical fracture surfaces of the molded materials: (a) compression-molded, (b) injection-molded, and (c) extruded samples.

For extruded samples, the batch was compounded directly using a counter-rotating twin-screw extruder with a filament die of $2.29 \mathrm{~mm}$ in diameter and $11.94 \mathrm{~mm}$ in length. The temperatures of the two heating sections of the barrel were set at 90 and $130^{\circ} \mathrm{C}$ and the die temperature and pressure at $130^{\circ} \mathrm{C}$ and $\sim 1 \mathrm{MPa}$, respectively. The rotational speed of the extruder screw was $40 \mathrm{rpm}$. The expandable microspheres were in situ foamed during the extrusion process since the processing temperature was high enough to foam the microspheres.

For the pyrolysis process, the formed samples were thermally cross-linked by heating the samples to $200^{\circ} \mathrm{C}$ in air. The crosslinked samples were then pyrolyzed at $1200^{\circ} \mathrm{C}$ for $1 \mathrm{~h}$ in argon at a heating rate of $1^{\circ} \mathrm{C} / \mathrm{min}$. The pyrolyzed compacts were then heated at $1450^{\circ} \mathrm{C}$ for $1 \mathrm{~h}$, for the carbothermal reduction of polysiloxane-derived SiOC by carbon black, and the results were subsequently sintered at $1750^{\circ} \mathrm{C}$ for $1 \mathrm{~h}$ in argon.

The bulk density of the porous ceramics was calculated from the weight-to-volume ratio of the samples. The porosity was determined from the ratio of bulk density to true density. The fracture surface morphology was observed by scanning electron microscopy (SEM, S4300, Hitachi Ltd., Japan). Using $\mathrm{Cu} \mathrm{K} \alpha$ radiation, X-ray diffractometry (XRD, D8 Discover, Bruker AXS $\mathrm{GmbH}$, Germany) was performed on ground powders. Compression tests were performed at room temperature at a constant crosshead speed of $0.5 \mathrm{~mm} / \mathrm{min}$ (Instron 4465, Instron Co., Ltd., USA).

The pyrolysis of the cross-linked compact consisting of polysiloxane, carbon black, microspheres, and $\mathrm{Al}_{2} \mathrm{O}_{3}-\mathrm{Y}_{2} \mathrm{O}_{3}$ additives at $1200^{\circ} \mathrm{C}$ involves the conversion of polysiloxane to an amorphous $\mathrm{Si}-\mathrm{O}-\mathrm{C}(\mathrm{SiOC})$. The microspheres are decomposed during the pyrolysis, resulting in porous SiOC containing free carbon and sintering additives. The subsequent carbothermal reduction of $\mathrm{SiOC}$ with $\mathrm{C}$ at $1450^{\circ} \mathrm{C}$ converts $\mathrm{SiOC}$ to $\beta$-SiC with the evolution of gaseous $\mathrm{CO}{ }^{18)}$ Further heat treatment at $1750^{\circ} \mathrm{C}$ with the aid of oxide additives leads to the liquid-phase sintering of the synthesized SiC. XRD analysis on all the ceramic foams prepared with the above processes showed the presence of $\beta$-SiC as a major phase and a trace of $\mathrm{Al}_{2} \mathrm{O}_{3}$ after sintering at a temperature of $1750^{\circ} \mathrm{C}$ for $1 \mathrm{~h}$.

Figure 1 shows the microstructures of molded samples. As shown, expandable microspheres were expanded upon heating and the expanded microspheres were embedded in a mixture of polysiloxane, carbon black, and $\mathrm{Al}_{2} \mathrm{O}_{3}-\mathrm{Y}_{2} \mathrm{O}_{3}$ powders. When the processing temperature is higher than the softening temperature of the thermoplastic shell (expandable microspheres), the liquid inside the shell undergoes gasifying which results in a dramatic increase in the volume of the microspheres. However, at temperatures above the temperature at which the highest expansion is obtained, the microspheres collapse gradually. In order to produce foaming by expanding the microspheres, the foaming temperature of the polysiloxane should also be higher than its softening temperature. On the other hand, the foaming temperature should be lower than the melting temperature of the microspheres, because otherwise the cells could easily collapse. In this work, we found that $150^{\circ} \mathrm{C}$ was a sufficient foaming temperature for the expandable microspheres and polysiloxane used. Thus, the expansion temperature in compression molding and the heating temperature in injection molding were both set as $150^{\circ} \mathrm{C}$. Most temperature settings in the extruder were at a relatively lower temperature than the desired temperature, because of the strong friction between screws and the feed material, which dissipated lots of heat during extrusion process, resulting in an increase of the temperature of the melt flowing through the die. ${ }^{28)}$ Although the die temperature was set as $130^{\circ} \mathrm{C}$ in the extrusion process, the actual temperature inside the die was higher $\left(\sim 150^{\circ} \mathrm{C}\right)$ than the setting temperature in this work.

The densities of the formed body were $1.094 \mathrm{~g} / \mathrm{cm}^{3}$ for the compression-molded sample, $1.085 \mathrm{~g} / \mathrm{cm}^{3}$ for the injectionmolded sample, and $0.535 \mathrm{~g} / \mathrm{cm}^{3}$ for the extruded sample. The sizes of expanded microspheres in compression-molded and injection-molded samples were similar $(\sim 30 \mu \mathrm{m})$. In contrast, the 

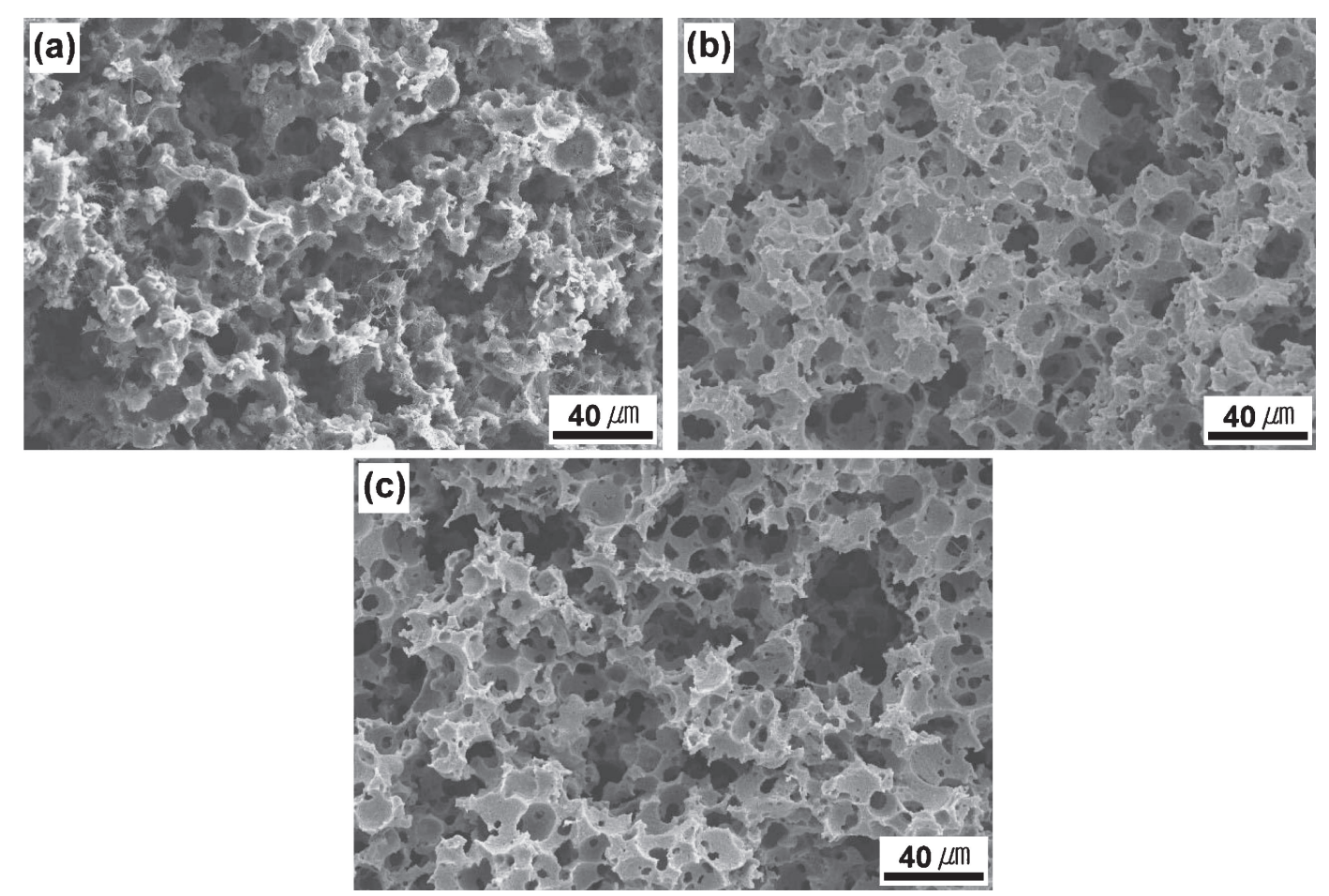

Fig. 2. Typical fracture surfaces of the porous $\mathrm{SiC}$ ceramics sintered at $1750^{\circ} \mathrm{C}$ for $1 \mathrm{~h}$ : (a) compression-molded, (b) injectionmolded, and (c) extruded samples.

average size of expanded microspheres in the extruded samples was $\sim 40 \mu \mathrm{m}$. Since the chemical composition and the content of expandable microspheres were all the same in the samples, the density of formed body was determined only by the degree of expansion of the expandable microspheres. Thus, the nearly identical densities obtained in both compression-molded and injection-molded samples were caused by the same expansion ratio of the microspheres, as evidenced by the same diameter of the expanded microspheres in the samples [Figs. 1(a) and 1(b)]. In contrast, the larger microspheres observed in extruded samples suggest that higher expansion of the microspheres took place in the extruded sample, and the higher expansion of the microspheres in the sample was most likely to have been caused by the free expansion condition without any constraint. Thus, a higher expansion of the microspheres during extrusion process led to a lower density of the formed body.

Typical microstructures of the sintered samples are shown in Fig. 2. As can be seen in Fig. 1(a), very fine $(15-25 \mu \mathrm{m})$, well distributed, open cells were achieved in compression-molded sample. In contrast, the microstructure of injection-molded sample consisted of small cells $(15-25 \mu \mathrm{m})$ and large pores $(30-50 \mu \mathrm{m})$. The microstructure of the extruded sample also consisted of small cells $(20-25 \mu \mathrm{m})$ and quite large pores $(30-100 \mu \mathrm{m})$. The homogeneous microstructure of compression-molded sample suggests that expandable microspheres were well distributed throughout the sample and the microspheres maintained their shape until their decomposition temperature was reached. In contrast, large pores observed in injection-molded and extruded samples were caused by the segregation of expandable microspheres during processing.

In the injection-molding process, an injection molding machine was directly connected with a twin-screw extruder. The starting materials were supplied to the twin-screw extruder and the mixture was then forwarded to the injection molding subsystem. The main reason for the high segregation was high shear near the wall of the cavity (the shaping mold) during filling and the

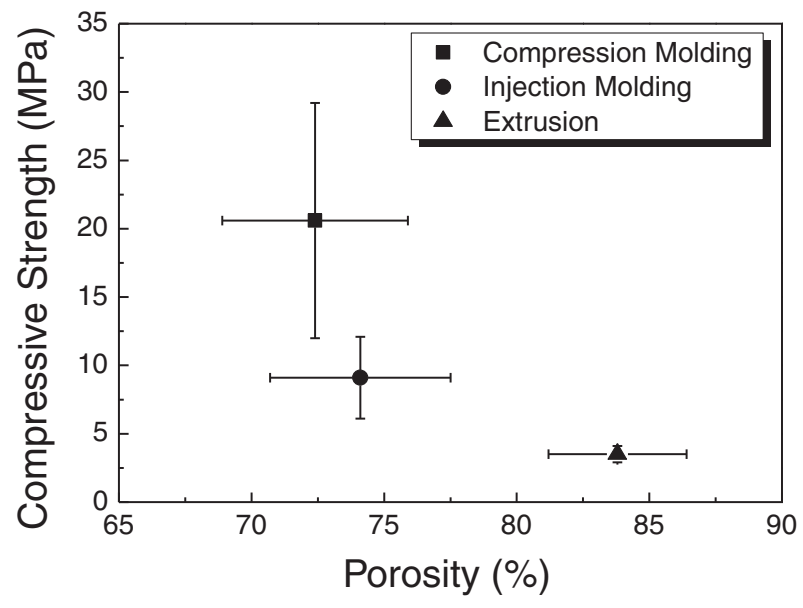

Fig. 3. Compressive strength of the porous $\mathrm{SiC}$ ceramics sintered at $1750^{\circ} \mathrm{C}$ for $1 \mathrm{~h}$ as a function of porosity.

residual stresses accumulated thereby. The high residual stress will cause the microspheres to move each other and thereby to cause their segregation. A partial segregation of the microspheres might also have taken place inside the accumulator because of large density difference between the microspheres $(<0.017$ $\left.\mathrm{g} / \mathrm{cm}^{3}\right)$ and molten polysiloxane $\left(1.036 \mathrm{~g} / \mathrm{cm}^{3}\right)$. The segregation of expanded microspheres could have caused the formation of large pores because the decomposition of the microspheres during pyrolysis led to the formation of pores. In the extrusion process, a larger expansion of expandable microspheres allowed more contact between them, as observed in Fig. 1(c), resulting in the formation of large pores after the removal of the microspheres by the pyrolysis process.

Figure 3 shows the compressive strength of the samples as a function of porosity. The strengths of compression-molded and injection-molded samples were $20.6 \mathrm{MPa}$ at $72.4 \%$ and $9.1 \mathrm{MPa}$ 

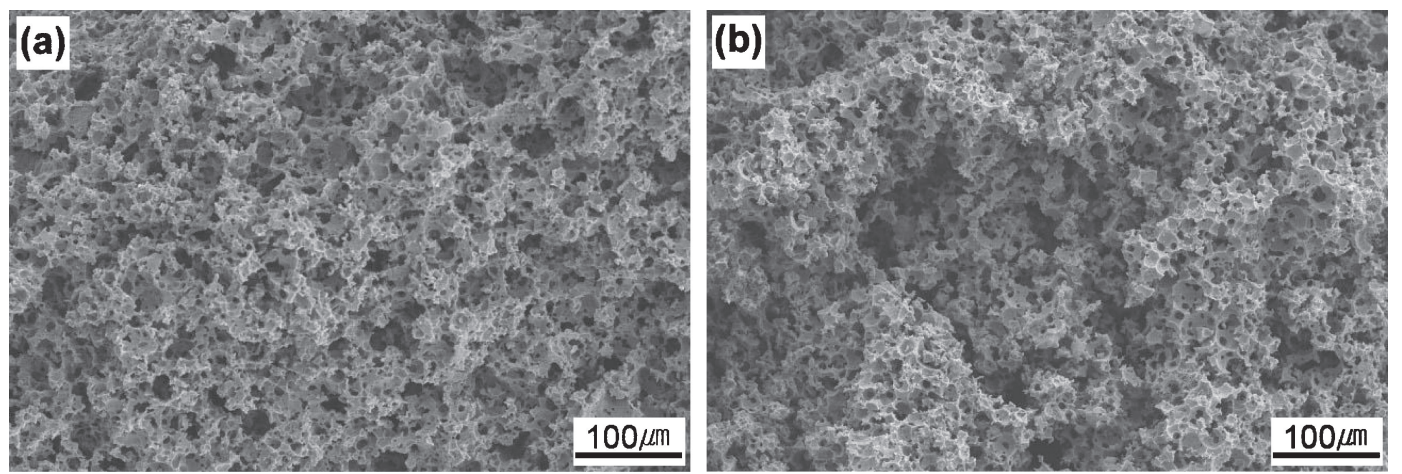

Fig. 4. Fracture surfaces of (a) compression-molded and (b) injection-molded samples at a low magnification. Note the presence of large pores in the injection-molded sample.

at $74.1 \%$ porosity, respectively. Although the porosity difference was quite small $(\sim 1.7 \%)$, the average compressive strength of the compression-molded samples was higher than 2 times of the average strength of injection-molded samples. Low magnification micrographs of both samples clearly showed that the compression-molded sample had more homogeneous microstructure than the injection-molded sample (Fig. 4). The injection-molded sample contained large pores with a diameter of up to $\sim 100 \mu \mathrm{m}$. The large pores were attributed to the segregation of expandable microspheres, as discussed earlier. The average compressive strength of extruded samples was $3.5 \mathrm{MPa}$ at $83.8 \%$ porosity. The relatively lower strength of the extruded samples, as opposed to that of the injection-molded samples, was caused by their increased porosity, wide pore size distribution, and presence of large pores caused by the higher expansion of the expandable microspheres during processing, as mentioned before. The present results also indicate that extrusion led to higher porosity $(\sim 84 \%)$ than the other forming methods $(72-74 \%)$ because of the higher expansion of the expandable microspheres, which was caused by free expansion.

The compressive strengths of these highly porous $\mathrm{SiC}$ ceramics are also compared to the previously obtained data. The compressive strength of porous $\mathrm{SiC}$ ceramics by a replica technique, a carbothermal reduction-sintering method, and a gelation-freezing method was $1.1 \mathrm{MPa}$ at $80.0 \%$ porosity, ${ }^{29)} 8.0 \mathrm{MPa}$ at $71.5 \%$ porosity, ${ }^{30)} 16.6 \mathrm{MPa}$ at $86.5 \%$ porosity, ${ }^{31)}$ respectively. The typical compressive strength of the present porous $\mathrm{SiC}$ ceramics were $20.6 \mathrm{MPa}$ at $72.4 \%$ porosity for compression-molded sample and $3.5 \mathrm{MPa}$ at $83.8 \%$ porosity for extruded sample. Thus, the compression-molded sample (20.6 MPa at $72.4 \%$ porosity) showed superior strength than the previously reported porous $\mathrm{SiC}$ ceramics $(8.0 \mathrm{MPa}$ at $71.5 \%$ porosity) fabricated by a carbothermal reduction-sintering process at the similar porosity. The extruded sample (3.5 MPa at $83.8 \%$ porosity) showed better strength than porous $\mathrm{SiC}$ ceramics (1.1 $\mathrm{MPa}$ at $80.0 \%$ porosity) fabricated by a replication method. However, the compressive strength values obtained here were lower than that $(16.6 \mathrm{MPa}$ at $86.5 \%$ porosity) of porous $\mathrm{SiC}$ ceramics fabricated by a gelation-freezing method. The excellent strength of the porous $\mathrm{SiC}$ ceramics fabricated by the gelation-freezing method may be partly attributed to the unidirectionally oriented micrometer-sized cylindrical pores. ${ }^{31)}$ The compressive strength of the porous $\mathrm{SiC}$ ceramics fabricated by the gelation-freezing method may be anisotropic because of the unidirectionally oriented cylindrical pores.

In summary, the present results suggest that (1) cost-effective polymer forming processes such as compression molding, injection molding, and extrusion can be used for fabricating porous
SiC ceramics from carbon-filled polysiloxane with expandable microspheres as a template; (2) the compression molding process leads to more homogeneous microstructure than the other forming methods, resulting in superior compressive strength (20.6 MPa at $72.4 \%$ porosity); (3) extrusion-molding leads to higher porosity $(\sim 84 \%)$ than the other forming methods $(72-74 \%)$ because of the higher expansion of the expandable microspheres; and (4) the injection molding process leads to a partial segregation of the expanded microspheres and results in the formation of large pores. The segregation of expanded microspheres may be minimized by shortening the duration of the batches at the accumulator before injection.

Acknowledgement This study was supported by the Mid-career Researcher Program through National Research Foundation of Korea (NRF) grant (No. 2010-0027502) funded by the Korea government (MEST).

\section{References}

1) S. Kitaoka, Y. Matsushima, C. Chen and H. Awaji, J. Am. Ceram. Soc., 87, 906-913 (2004).

2) H. Tanaka, T. Nishimura, N. Hirosaki and D. H. Jeong, J. Ceram. Soc. Japan, 113, 51-54 (2005).

3) M. Fukushima, Y. Zhou, H. Miyazaki, Y. Yoshizawa, K. Hirao, Y. Iwamoto, S. Yamazaki and T. Nagano, J. Am. Ceram. Soc., 89, 1523-1529 (2006).

4) T. Nagano, K. Sato, T. Saitoh and Y. Iwamoto, J. Ceram. Soc. Japan, 114, 533-538 (2006).

5) R. A. Wach, M. Sugimoto and M. Yoshikawa, J. Am. Ceram. Soc., 90, 275-278 (2007).

6) F. Kawamura, H. Yamane, T. Tamada, S. Yin and T. Sato, J. Am. Ceram. Soc., 91, 51-55 (2008).

7) M. Fukushima, Y. Zhou, Y. Yoshizawa and K. Hirao, J. Eur. Ceram. Soc., 28, 1043-1048 (2008).

8) H. Yamane, F. Kawamura and T. Yamada, J. Ceram. Soc. Japan, 116, 163-165 (2008).

9) M. Fukushima, Y. Zhou and Y. Yoshizawa, J. Membr. Sci., 339, 78-84 (2009).

10) S. Shimada, M. Murata and M. Narisawa, J. Am. Ceram. Soc., 92, 21-25 (2009).

11) B. V. Manoj Kumar and Y.-W. Kim, Sci. Technol. Adv. Mater., 11, 044303 (2010)

12) Y.-W. Kim, Y.-J. Jin, J.-H. Eom, I.-H. Song and H.-D. Kim, J. Mater. Sci., 45, 2808-2815 (2010).

13) H. Yamane, T. Shirai, H. Morito, T. Yamada, Y. Hasegawa and T. Ikeda, J. Eur. Ceram. Soc., 31, 409-413 (2011).

14) M. Kotani, K. Nishiyabu, S. Matsuzaki and S. Tanaka, J. Ceram. Soc. Japan, 119, 563-569 (2011).

15) P. Colombo, G. Mera, R. Riedel and G. D. Soraru, J. Am. Ceram. Soc., 93, 1805-1837 (2010). 
16) Y. J. Jin and Y.-W. Kim, J. Mater. Sci., 45, 282-285 (2010).

17) R. Haug, M. Weinmann, J. Bill and F. Aldinger, J. Eur. Ceram. Soc., 19, 1-6 (1999).

18) Y.-W. Kim, J. H. Eom, C. Wang and C. B. Park, J. Am. Ceram. Soc., 91, 1361-1364 (2008).

19) Y.-W. Kim, J. H. Eom, C. B. Park, W. Zhai, Y. Guo and M. Balasubramanian, J. Am. Ceram. Soc., 93, 3099-3101 (2010).

20) J. Zeschky, F. Goetz-Neunhoeffer, J. Neubauer, L. S. H. Jason, B. Kummer, M. Scheffler and P. Greil, Compos. Sci. Technol., 63, 2361-2370 (2003).

21) Y.-W. Kim, S. H. Kim, C. Wang and C. B. Park, J. Am. Ceram. Soc., 86, 2231-2233 (2003).

22) P. Colombo, J. Eur. Ceram. Soc., 28, 1389-1395 (2008).

23) M. Fukushima and P. Colombo, J. Eur. Ceram. Soc., 32, 503510 (2012).
24) F. Wolff and H. Munstedt, J. Mater. Sci., 46, 6162-6167 (2011).

25) T. Zhang, J. R. G. Evans and J. Woodthorpe, J. Eur. Ceram. Soc., 15, 729-734 (1995).

26) S. Walter, D. Suttor, T. Erny, B. Hahn and P. Greil, J. Eur. Ceram. Soc., 16, 387-393 (1996).

27) Y.-W. Kim, J. H. Eom, Y. Guo, W. Zhai, C. B. Park and I. H. Song, J. Am. Ceram. Soc., 94, 344-347 (2011).

28) C. Wang, J. Wang, C. B. Park and Y.-W. Kim, J. Mater. Sci., 42, 2854-2861 (2007).

29) X. Zhu, D. Jiang and S. Tan, Mater. Sci. Eng., A, 323, 232-238 (2002).

30) J. H. Eom and Y.-W. Kim, J. Mater. Sci., 44, 4482-4486 (2009).

31) M. Fukushima, M. Nakata, Y. Zhou, T. Ohji and Y. Yoshizawa, J. Eur. Ceram. Soc., 30, 2889-2896 (2010). 